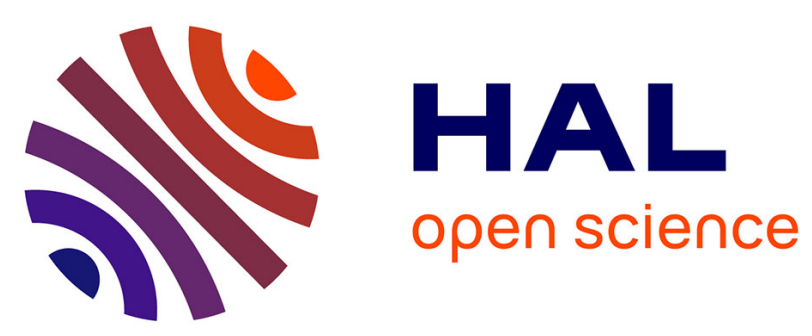

\title{
True water constraint under a rainfall interception experiment in a Mediterranean shrubland (Northern Tunisia): confronting discrete measurements with a plant-soil water budget model
}

D. Longepierre, F. Mouillot, B. Ouelhazi, J.M. Ourcival, Alain A. Rocheteau, D. Degueldre

\section{To cite this version:}

D. Longepierre, F. Mouillot, B. Ouelhazi, J.M. Ourcival, Alain A. Rocheteau, et al.. True water constraint under a rainfall interception experiment in a Mediterranean shrubland (Northern Tunisia): confronting discrete measurements with a plant-soil water budget model. Plant Ecology, 2014, pp.33. 10.1007/s11258-014-0349-4 . hal-01049490

\author{
HAL Id: hal-01049490 \\ https://hal.science/hal-01049490
}

Submitted on 17 Sep 2014

HAL is a multi-disciplinary open access archive for the deposit and dissemination of scientific research documents, whether they are published or not. The documents may come from teaching and research institutions in France or abroad, or from public or private research centers.
L'archive ouverte pluridisciplinaire $\mathbf{H A L}$, est destinée au dépôt et à la diffusion de documents scientifiques de niveau recherche, publiés ou non, émanant des établissements d'enseignement et de recherche français ou étrangers, des laboratoires publics ou privés. 


\section{Plant Ecology, special issue "Living with extremes"}

True water constraint under a rainfall interception experiment in a Mediterranean shrubland (Northern Tunisia): confronting discrete measurements with a plant-soil water budget model.

Longepierre D.(1), Mouillot F.(1), Ouelhazi B.(1,3), Ourcival J.M.(2), Rocheteau A.(1), Degueldre D.(2)

1 IRD, equipe DREAM, UMR CEFE, 1919 route de Mende, 34293 Montpellier cedex 5, France

2 CNRS, equipe DREAM, UMR CEFE, 1919 route de Mende, 34293 Montpellier Cedex 5, France

3 INRGREF, Rue Hédi Elkarray, BP n 10 2080, Ariana, Tunisia 


\section{Abstract}

2 Increased drought length and intensity is expected in the Mediterranean basin under

3 anthropogenic increase in atmospheric $\mathrm{CO} 2$, leading to extreme events not yet

4 encountered in the present climate variability. Understanding ecosystems responses

5 and capturing peculiar ecophysiological processes related to these events have been

6 investigated in the field by rainfall manipulation experiments. Quantifying the actual

7 drought faced by the ecosystem under control and dry plots, or among experiments

8 remain a key challenge for explaining functional impacts on plant growth. Full profile

9 soil water content can be tricky to assess in rocky soils, and time consuming plant water potential measurements remain a discrete information unable to capture short rainfall pulses. We propose here to fully investigate the water budget of a total rainfall interception manipulation on a Mediterranean shrubland, coupled with a plant-soil water balance model. We could accurately simulate the seasonal course of plant water status, including small rainfall pulses. We then derived yearly estimates of Water Stress Integral for each water treatment leading to an estimate of $66 \%$ to $86 \%$ increase of drought intensity for the dry treatment compared to the control. Comparing actual and expected plant water budget from simulations in the dry plots allowed to identify and quantify the impact of methodological issues related to rainfall interception experiments as side effects for intrusive rain drops and subsurface lateral water flow.

\section{Keywords : Drought; climate change; extreme event; rainfall interception experiment;} Mediterranean climate; shrubland; water model 
Introduction

3

Water limited ecosystems experience recurrent dry spells, leading to prolonged soil water deficit. The timing, duration and intensity of these drought periods are critical variables for ecosystem functioning and can be highly variable in space and time (Ruffault et al. 2013). They control the seasonal pattern of plant water status, stomatal

conductance for leaf gaz exchanges, and in turn leaf phenology, carbon assimilation, plant growth, seed production, and fuel combustibility leading to increasing fire risk (REF). Plant response to this rainfall deficit can however be very heterogeneous, according to soil available water content and species ecophysiological traits for water use (Ackerly 2004, Galmes et al. 2007, Joffre et al. 1999, Quero et al. 2011, Tardieu and Simmoneau 1998, West et al. 2012), including root profile, leaf area index and its phenology or water use strategies. In turn, widely used meteorological drought indices (Dai 2010, Keyantash and Dracup 2012), might be misleading in quantifying actual drought experienced by plants.

In the global context of climate change, and particularly increasing drought predicted globally, more prolonged drought periods are expected, with a higher frequency of the presently observed extreme events, and/or the emergence of more extreme events not yet encountered. To capture the effects of these extreme events on ecosystem functioning and sustainability, rainfall manipulation experiments have been recently developed to simulate these prolonged dry spells on site ( see for review and futur challenges Beier et al. 2012, Jentz et al. 2007, Wu et al. 2011, Vicca et al. 2012). Methods include either partial rainfall interception by permanent gutter removing a constant portion of precipitation for each single rainfall event, or moving shelters intercepting all precipitations during a prolonged period. These experiments can be coupled with watering systems as control plots of well watered conditions. Comparing the results of these experiments recently raised the problem of quantifying the drought 
1 intensity actually applied to the studied ecosystems (Vicca et al. 2012). If the rainfall 2 interception methods are somehow standard between experiments, registered 3 variables can be heterogeneous according to technical issues. Daily or hourly 4 meteorological variables are common available datasets registered through experiments for comparison, but drought is more precisely approached through soil water content from automated probes or plant water status through fuel moisture content or species predawn water potentials. The before-mentioned technical issues include the insertion of soil water probes in the deepest soil layers when soil is rocky, or the temporal frequency of time-consuming predawn water potential measurements in mixed ecosystems with heterogeneous water use strategies among species. These issues can lead to an incomplete understanding of the ecosystem water budget. Between-site intercomparisons, or even quantification of the actual drought over the whole dry season between control and dry plots can be difficult or misleading when based only on the rainfall amount or sparse information on plant water status. Particularly rainfall pulses have been shown to be significant contributors of plant functioning in water-limited ecosystems (Sala and Lauenroth 1982), and can be missed when the time elapsed between two field measurements exceeds the effect of these rain pulses.

Mediterranean ecosystems have to cope with summer drought and climate scenarios predict an increase of summer rainfall deficit leading to more prolonged drought events (Giorgi and Lionello 2008). We investigated the effects of these prolonged drought on a mixed Mediterranean shrubland equipped with a moving shelter to simulate a seven month total dry spell in Northern Tunisia (North Africa), at the transition zone with semiarid climate the most susceptible to be affected by climate change. We completed a refined campaign of measurements across the dry season to capture both the soil and plant water status with a special focus on rainfall pulses, deep soil water measurements, and inter-individual analysis. Our objectives were i) to investigate precisely the soil water budget across the whole soil profile to indentify potential 
methodological issues related to rainfall interception experiments as deep soil water diffusion or intrusive rain drops inside the experimental plot from lateral wind or during the time elapsed to unroll the shelter, ii) identify the daily processes of plant response to soil water content and rain pulses in order to iii) calibrate a plant-soil water budget able to simulate the daily time course of plant water potentials across the summer season when measurements are lacking. We used this model to quantify actual water stress integral across the season for comparing treatments, and to further discuss plant water budget during these dry events, and raise potential methodological issues to be considered in rainfall interception experiments.

\section{Material and Methods}

1.1 Study site

The study was conducted in the Kroumirie territory of Northern Tunisia (North Africa) near the village of Souk El Jema (Fernana, adminsitrative governorate of Jendouba; $\left.36.605^{\circ} \mathrm{N}, 8.566^{\circ} \mathrm{E}\right)($ Figure 1$)$. The study area is located on a NWfacing $20 \%$ slope, at an altitude of $529 \mathrm{~m}$. The region is characterized by a Mediterranean climate, with long, dry, and warm summers. Mean annual temperature is $14.6^{\circ} \mathrm{C}$, varying between $10^{\circ} \mathrm{C}$ in January and $28^{\circ} \mathrm{C}$ in August. Mean annual rainfall is $750 \mathrm{~mm} \mathrm{(5 \%} \mathrm{in} \mathrm{summer,} 31 \%$ in autumn, $29 \%$ in spring, and $35 \%$ in winter), with high inter-annual variability but usually with two or three months of summer drought (source Institut National de la Météorologie, Tunisia, and Direction Générale des Ressources en Eau, Tunisia). The study area is covered by a Mediterranean shrubland composed of Cistus monspeliensis L., Erica arborea L., Phillyrea latifolia L., Pistacia lentiscus, Callychtoma vilosa, and Arbutus unedo. Soil texture is sandy clay $(65 \%, 23 \%$, and $12 \%$ sand, clay and loam, respectively), with a low proportion of rock $(<5 \%), 2.5 \%$ organic matter, and $\mathrm{pH}=6$. The stand $(100$ $\mathrm{m} \times 70 \mathrm{~m}$ ) was initially fenced to prevent damage from wild and domestic large ungulate, and twenty $6 \mathrm{~m} \times 6 \mathrm{~m}$ plots were selected. The plots were assigned to 
five treatments (four plots per treatment), following a randomized, complete block design, with four blocks arranged parallel to the slope. Plots were subjected to rainfall manipulations as described below.

\subsection{Rainfall interception protocol}

A $6 \mathrm{~m} \times 6 \mathrm{~m}$ steel frame $(0.1 \mathrm{~m}$ width) was installed in all rainfall manipulation plots 2 $\mathrm{m}$ above ground. Four steel posts $(2.0 \mathrm{~m} \times 0.1 \mathrm{~m} \times 0.1 \mathrm{~m})$ supported the frame, each inserted $0.5 \mathrm{~m}$ into the soil. 8 cables were used to maintain the structure. A $6 \mathrm{~m} \times 6$ $\mathrm{m}$ single white PVC sheet (2 mm thick) was installed on top of each base structure. The PVC shelters unfold and fold by sliding through cables crossing the frame, manually driven by the 3 permanent security staff ensuring site safety. This manual system was preferred to the automated one (Misson et al. 2011, Parra et al. 2012) as the site was 3 hours drive from Tunis so it was not possible to quickly repair any system's failure, and the site had to be secured by permanent staff. A time lag of 20 minutes was needed to unroll all the shelters, usually before rainfall started as the staff was warned of weather forecasts, and no failure happened during the experiment. Surface run-off water flowing towards the plot was diverted by digging a $50 \mathrm{~cm}$ trench on the upper and side part of the plots. The studied individual plants were only considered in the central $5 \mathrm{~m} \times 5 \mathrm{~m}$ area within the $6 \mathrm{~m} \times 6 \mathrm{~m}$ area covered by the shelters to try and prevent side effects. Water for irrigation was pumped through a pipeline system by a hydraulic pressure bomb (600 I.min-1, pressure 3 bars) from a container $(5,000 \mathrm{~L}$ of total storage) located on the upper part of the stand. The container was refilled after each irrigation by a truck delivering water from the closest water spring. Plot irrigation was performed manually at night with water pipes equipped with analogic counters and sprinklers. The full experimental design and micro-meterological effects have been earlier described and tested in Parra et al. (2012) for a similar experiment in Spain. We'll explore here only the two 
most contrasted treatments: i) the Severe Dry (SD) treatment was a total rainfall exclusion from May to October in 2011 (6months) and April to October in 2012 (7months), and ii) the Environmental Control (EC) was the actual rainfall pattern with summer watering when monthly rainfall was below the historical records. Each treatment was composed in 2011 of 8 replicates for EC, 4 replicates of SD, and 3 replicates for EC and SD in 2012 (due to some plots burned at the end of 2011 for post fire regeneration assessment, results not shown here). The simulated rainfall patterns of a lengthened summer drought and precipitation concentrated in winter were consistent with projections for the Mediterranean region (Christensen et al. 2007).

\subsection{Field measurements}

We installed a fully automated meteorological station on the site with data acquisition starting April $9^{\text {th }}$ 2011. The station registered on a 5-minute time step (then averaged on a $30 \mathrm{~min}$ time step) air temperature $\left({ }^{\circ} \mathrm{C}\right.$, sensor Campbell HMP155A), air humidity (\%), VPD (vapor pressure deficit), global solar radiation (W.m-2, sensor Campbell SP1110), PAR (Photosynthetic Active Radiation, mmol.m-1.s-1, sensor Campbell SKP215), wind speed (m.s-1, sensor Campbell A100R) and precipitation (mm, sensor ARG100). Data were stored in a data logger and downloaded for data checking on a monthly basis. Energy is supplied by a solar panel Photowatt 40Wc. Daily time courses of temperatures (minimum, maxium and mean), precipitation and solar radiation for the 2011-2012 period are presented in figure 2 .

Volumetric sol water content (\%) was registered for three soil depths in each plot using automated probes buried in the center of each plot. A Decagon probe $(5 \mathrm{HS}$, Decagon Devices, United States) installed horizontally at $3 \mathrm{~cm}$ depth registered the sol water content for the layer $1-5 \mathrm{~cm}$ and a Decagon probe $(10 \mathrm{HS}$ Decagon Devices, United States) also installed horizontally registered soil water content for 
the layer $5-15 \mathrm{~cm}$. The deep soil water content was registered with a Campbell CS616 (Campbell Scientific, United States) probe $(15-45 \mathrm{~cm})$ installed vertically. Data were continuously recorded on a 5-minute time step, and averaged at 30 minutes intervals.

Experimental measurements consisted of leaf predawn water potentials with a pressure chamber (PMS 1000, PMS Instruments, Corvallis, OR, USA) monitored before sunrise, with a scheduled interval of one month. Additional measurements were performed before and after some rainfall/irrigation events during the summer season to capture rain pulse effects on plant water potentials. Among the panel of species present on the site, we selected two anisohydric species (sensu Tardieu and Simmoneau 1998) for which plant water potentials were the lowest during the dry period and have been assumed to be the closest to soil water potential : Erica arborea and Arbutus unedo. For each species one individual per plot was selected with the most central position in the plot, even if the heterogenous composition of the plots induced individuals to be actually located at the border of the $5 \mathrm{~m} \times 5 \mathrm{~m}$ inner plot.

\subsection{Soil/plant water budget model}

We used a plant-soil water budget model to simulate daily soil water content, evaporation and plant transpiration fluxes, and the subsequent plant water potential. Variations in soil water content (SWC) were simulated using the water module from the SIERRA process-based vegetation model (Mouillot et al. 2001, Ruffault et al. 2013), based on the water balance between precipitations and water outputs.

$$
\Delta S W C=P-\ln -D-E-T
$$

Where the $\mathrm{P}$ is daily precipitation $(\mathrm{mm}), \mathrm{In}$ is the amount of precipitation intercepted by the canopy $(\mathrm{mm}), \mathrm{E}$ is bare soil evaporation $(\mathrm{mm})$ and $\mathrm{T}$ is transpiration $(\mathrm{mm})$. is the resulting deep water drainage. Soil is represented by a 4 layer bucket model 
(depths $0-5 \mathrm{~cm}, 5-15 \mathrm{~cm}, 15-45 \mathrm{~cm}, 45-100 \mathrm{~cm}$ ). Reference evapotranspiration ET0 was computed using the Penman-Monteith equation ( $R$ cran Package Sirad, function ET0, from Allen et al. 1998). In our two-step approach (Shuttleworth (2007) for a review of water budget models), reference evapotranspiration ET0 is controlled by a canopy resistance and a water stress scalar to get the actual transpiration $\mathrm{T}$. This simplified version of the full Penman-Monteith (Penman 1948, Monteith 1965) approach has been used for forested ecosystems in the same area (Chakroun et al. 2014). Stomatal conductance is simulated using soil water potential, related to soil water content by the power function model of the retention curve (Van Genuschten 1980). The power function was fitted to the soil water content/plant water relationship from field measurements.

Species functional parameters were Leaf Area Index, rooting depth, minimum water potential for extraction ( $\Psi \lim )$, and were kept constant throughout the simulation with respectively values of $2.0(+/-0.2), 1.0 \mathrm{~m}$, and $-7 \mathrm{MPa}$. From this initial model, we added a diffusion soil water flux from upper layers to the subsequent deeper ones when relative water content of the upper layer was greater than the lower ones according to the Darcy's law for vertical unsaturated flow (Muller 1999 and used in Belk et al. 2007). We also computed water potentials for the whole plant as a combination of simulated soil water potentials where the whole plant water potential was $30 \%$ of the minimum water potential for soil layers 1 and 2 , and $70 \%$ of the minimum water potential for soil layers 3 and 4 .

\subsection{Numerical experiment}

We first calibrated model's parameters from field measurements for an accurate simulation of both soil water content and plant water potentials under current climate in control plots for the year 2012. The model was then run under rainfall interception climate scenario with the previously calibrated model to estimate the expected soil plant water budget in the dry plot (SD-H1). Discrepancies between 
simulated and actual soil/plant water budget were then investigated according to two hypothesis: i) SD-H2: $20 \%$ of the registered rainfall was able to reach the soil under the shelter under windy conditions and horizontal rain direction, and ii) SDH3: SD-H2 with, in addition some deep soil water which could diffuse into the SD plot from wetter soil conditions outside of the plot (the soil water budget of the deeper layer was issued from the EC water budget, and not the SD).

The Water Stress Integral (WSI) was finally calculated yearly as the integral of simulated daily predawn leaf water potentials along the year (Myers 1988, Wullschleger and Hanson 2006). It was used as the index quantifying actually drought occurring on each experimental plot.

\section{Results}

\subsection{Seasonal course of soil water content}

Field measurements of soil water content for the three soil layers $(0-5 \mathrm{~cm}, 5-15 \mathrm{~cm}$, $15-45 \mathrm{~cm}$ ) for the years 2011 and 2012 are presented in figure 3 . The SD treatment did not receive any rainfall during the whole period while the $\mathrm{EC}$ treatment received $190 \mathrm{~mm}$ in 2011 and $353 \mathrm{~mm}$ in 2012 according to the rainfall distribution presented in figure 2. We'll note here that 2011 is more characterized by heavy spring rainfalls (around Day Of the Year DOY=150) while 2012 is more characterized by a drier spring and a wetter fall period (heavy rainfall events around DOY 240 and 260). No major difference in temperature nor solar radiation between the two periods was observed (figure 2). The soil water measurements illustrate that the three layers were at field capacity at the beginning of the experiment (15mm, 30mm and $90 \mathrm{~mm}$ for the three layers respectively). We then observe an earlier drying of the two upper layers for both years. For the third layer, the earlier drying of 2011 was not observed in 2012 as no major rainfall event happened after 
day 120 compared to 2011. After DOY 180, all the plots reached their minimum water content, whatever the treatment. From this date onwards, the SD treatment kept constant dry soil water content until DOY 280 . The shelters were still installed until DOY 320, but the heavy rainfalls during consecutive days around DOY 280 lead to partial intrusive water in the SD plots for the three layers and both years 2011 and 2012. The soil water content was still much lower than the EC plots. For these EC plots, soil water content along the season was marked by peaks of high moisture when significant rainfalls occured $(>10 \mathrm{~mm})$. These peaks lasted for about 10 to 15 days only. In turn, the two heavy rainfall events at DOY 240 and 260 in 2012, lead to similar soil water content at DOY 280 for both treatments. From DOY 280 until the end of the experiment, soil water content was at field capacity for the EC plot. We can conclude from these results, that, along a $45 \mathrm{~cm}$ soil profile, both treatments reached the same soil water content at their driest. However, the SD plots were marked by a slight earlier drying in spring, a significant later rewetting in fall, and the absence of high soil moisture pulses during the summer period.

\subsection{Plant water status}

Figure 4 represents the seasonal measurements of predawn leaf water potentials (LWP) for Erica arborea and Arbutus unedo in the SD and EC plots for 2011 and 2012. Measurements were scheduled on a monthly basis. To ensure for relevant information, more intense field campaigns were performed before and after some few rainfall/irrigation events. For both treatments, LWP was close to $-0.5 \mathrm{Mpa}$ at the beginning of the experiment ensuring a similar initial water status. LWP slowly decreased in spring to reach -3Mpa at DOY 200 with no significant differences between the treatments. The lowest values of $-6.8 \mathrm{Mpa}$ were obtained at the end of the summer in 2011 and 2012 and for both treatments with no significant differences. 
Differences between treatments were observed on one hand after DOY 250 for both years when LWP was measured at -4MPa in 2011 and $-0.5 \mathrm{MPa}$ in 2012 in the EC plots where rainfall occured, but significantly lower in the SD plots (-6Mpa and 5Mpa in 2011 and 2012 respectively). We noticed however high standard deviations (sd) in the measurements in the SD plots after DOY 250 in 2012 (sd=+/$3 \mathrm{MPa}$ compared to $s d=+/-0.8 \mathrm{MPa}$ before DOY 250 ), particularly just after rainfall events of DOY 260 and 280 in the site, when some individuals were measured at 6.5 $\mathrm{MPa}$ and other at $-1 \mathrm{MPa}$ within the same treatment. This high standard deviation is not noticed in the EC plot for the same dates. On the other hand, differences in LWP between the two treatments were noticed during small rainfall events during the dry season (DOY 210 and 222 in 2012 for example). Measurements were performed just before and after the rainfall event, so we could identify that pre-rainfall LWP were at $-6.8 \mathrm{MPa}$, and rapidly switched to $-4 \mathrm{Mpa}$ the day after. Standard deviation after the rainfall was also much higher than before. When comparing with the soil water content at this date, we can see that this change of LWP was not associated with significant changes in the total soil water content (as the rainfall was only $6 \mathrm{~mm}$ ), but little changes only in the upper soil layer.

As a conclusion from these results, we could show that the rainfall interception experiment induced neither significant differences in LWP during the spring period, nor in the minimum LWP reached during the summer season. From discrete LWP measurements, major differences were only detected at the end of the dry season and following small rainfall events. We could detect these differences because of an appropriate field campaign not based on an a priori schedule but arranged according to weather. Post-rainfall measurements at the end of the dry season also revealed a high standard deviation between individuals, and that could have been missed with a monthly schedule. Based on these observations where we can identify the need for more frequent LWP to accurately capture all the variations of 
LPW along the season, we used a plant-soil water budget model to simulate a continuous course of LWP to better capture the small events all along the experiment, including the missed ones in the measurement framework.

\subsection{Modelling soil-plant water budget}

We finally used a process-based soil-plant water budget model to simulate the daily time course of soil water content and LWP. The model was calibrated for the year 2012 on the control treatment and further used for 2011 and the dry treatment for validation. Figure $4 \mathrm{~A}$ represent the daily time course of simulated soil water content and LWP for the two treatments and for years 2011 and 2012. We observe that simulations and observations fairly agree with $R^{2}=0.86$ and 0.83 for the EC plot respectively in 2011 and 2012 (figure 4B). $R^{2}$ is 0.84 for the SD plot in 2011 when field measurements were made before rainfall events, but falls to $R^{2}=0.48$ when a more thorough field campaign was performed in 2012 with pre and post rainfall measurements.

From these simulations we can identify that we were able to simulate the slow spring decrease in LWP, and an accurate representation of summer LWP pulses induced by small rainfall events. When focusing on this peculiar events (figure 5), we were able to reproduce both the intensity of changes in LWP before and after the rainfall, and the subsequent LWP decay during the post-rainfall drying period. We tested for the model's sensitivity to LAl, a key variable for water budget and locally varying between the plots (from 1.8 to 2.2). Uncertainties in the resulting simulated LWP is presented in figure 4 , and were mostly observed in the LWP decreasing phase. We were then confident in the stated hypothesis in the plant water model for simulating plant water status based on soil water content, for a further use in quantifying the rainfall interception efficiency.

\subsection{Water budget under rainfall interception}


From our soil-plant water budget model validated on the control treatments, we performed a simulation run for 2011 and 2012 with no rainfall all along the period (figure 6). The simulated soil water budget showed a lower than observed soil water content during the drying phase in spring under scenario SD-H1, with about a time lag of 30 to 35 days (figure 4). These discrepancies are also observed in the LWP simulations under the SD-H1 scenario (figure 6). The model then simulated a maintenance of LWP at -7Mpa all along the dry season from DOY 180 to 320 . This result is partly in accordance with the field measurements where some individuals actually kept a similar low LWP around -7MPa until late in the season in the dry treatment and did not exceed this value. However, as we mentioned in the LWP results description, we observe a high inter-individual variability after DOY 260 when heavy rainfalls occurred on the site. We then tested the hypothesis that some individuals would be affected under SD $\mathrm{H} 2$ and SD $\mathrm{H} 3$ hypothesis. Figure 6 represents the plant water budget under these two additional hypothesis and illustrates how they would actually affect plant water status. With these simulations, we produced a range of variability in accordance with field measurements, where LWP can vary from $-7 \mathrm{Mpa}$ under the SD $\mathrm{H} 1$ scenario, and up to $-3 \mathrm{MPa}$ if water enters the system under SD H2 scenario. $R^{2}$ between observed and simulated LWP was increased from 0.48 under SD H1 scenario to 0.59 under SD H2 and SDH3 scenarios. They were accounted for the overall estimate of the experimental drought intensity through the Water Stress Integral.

\subsection{Quantifying rainfall interception efficiency through Water Stress Integral}

We finally quantified the efficiency of our rainfall interception experiment by comparing the water stress integral WSI for the EC, and SD experiments covering experimental bias stated in hypothesis SD H2 and SD H3. WSI for the EC plot was -425 (+/- 34) MPa and -434 (+/- 30) MPa for 2011 and 2012 respectively (figure 7). 
This value was $-790(+/-35) \mathrm{MPa}$ and $-1025(+/-25 \mathrm{MPa})$ for the expected WSI under rainfall interception SD H1 hypothesis respectively for 2011 and 2012. We estimated finally the actual WSI under SD H3 scenario to be $-699(+/-35 \mathrm{MPa})$ for 2011 and -752 (+/-32Mpa) for 2012. In turn, from an initial hypothesis where a 30\% rainfall interception was performed, the resulting impact on WSI was a $+64-73 \%$ increase, lower than the expected $86-136 \%$ increase if the rainfall interception was actually complete. From this final yearly value, the seasonal time course of cumulated water potentials (figure 7 ) shows that we reached a $15 \%$ increase of WSI at the end of summer (DOY 250). The main difference in the treatments for the yearly WSI was mostly due to the fall period difference between treatments when the deeper soil layer is dry.

\section{Discussion}

\subsection{Soil water content and plant water potential relationship}

It is widely assumed, for comparative ecological performances or modelling purposes that plant predawn water potentials reflect the wettest soil potential accessed by roots. In this hypothesis, plants are able to recover from their diurnal water depletion by absorbing water from the different soil layers until plant water potential reaches the water potential in this soil layer. In turn, as long as a soil layer is enough watered for providing a gradient of potentials between the soil and the plant, a water flux happens. This assumes a non-steady-state phase between plant and soil, where the plant water content is represented by a reservoir depleted during the day and refilled at night when no transpiration occurs but root water uptake happens (Lhomme et al. 2001). There are however evidences of predawn disequilibrium (PDD) in water-limited ecosystems as a response to peculiar ecophysiological processes as night-time transpiration or leaf apoplastic solutes for 
a resistance to rehydratation (Donovan et al. 2003). Beside this observed process of PDD in some semi-arid conditions, the predawn soil-plant water potential equilibrium presents exceptions when soil water content is markedly heterogeneous among different soil layers (Ameglio et al. 1999). This partial rootzone drying (PRD) is actually a common event in the deficit irrigation practice, where water from irrigation is only provided in the upper part of the root profile while deeper roots remain in dry conditions. This practice is widely applied for permanent crops as olive trees in the Mediterranean basin (Fernandez et al. 2003, Ghrab et al. 2013). The objective is to reactivate gaz exchanges at the canopy level and in turn plant functioning under drought conditions, but with a maximum water saving strategy as rehydrating part of the soil profile is enough for providing plant water potentials suitable for stomatal aperture. This peculiar practice is actually close to our natural and experimental conditions in the studied area, where small rainfall/watering events during the summer drought rehydrate the upper soil layers without refilling the deeper layers, or on the contrary when the upper soil layers start to dry out in late spring while the deeper layer is still well watered. We could indeed identify that rainfall events of 5 to $15 \mathrm{~mm}$ could refill the upper soil layer to field capacity and have significant impact in reducing the plant predawn water potential. However, we never reached predawn water potentials at the level of potentials observed during winter when the whole soil profile is at field capacity. In turn, the hypothesis of the minimum soil water potential to be retained for approximating the plant water potential was discarded, and adjusted as explained in the model description. As the plant functioning period in water limited ecosystems is constrained by stomatal closure and plant water potentials, understanding the plant response to partial soil water refill appears as a key process to further investigate in plant ecology. 
Our results indicated that small rainfall events during dry periods are able to provide substantial, even if not complete, recovery of plant water potential closer to $0.5 \mathrm{MPa}$ through the soil surface rewetting. This change in plant water status is usually associated with an increase in stomatal conductance, transpiration flux and photosynthesis (Loik et al. 2007). In semi arid ecosystems, implications for carbone assimilation (Huxman et al. 2004) and plant growth can be significant (Ramirez et al. 2012). These pulses are however hard to detect in the discrete sampling of plant predawn water potential, the key variable used for comparing plant water status. We suggest here to be more carefull on these pulses under Mediterranean climate, and particularly for shallow rooted species as shrublands, to accurately account for the actual drought experienced by plants along the summer season. These pulses could be highly significant for shrublands with a subsequent ecological role aleady identified for arid ecosystems (Sala and Lauenroth 1982, Schwinning and Ehleringer 2001, Schwinning and Sala 2004). For deep-rooted forested species, extreme drought could be more dependant on changes in winter precipitation refilling or not the deep soil water content (Yaseef et al. 2009, Limousin et al. 2009).

The threshold-delay conceptual model (Ogle and Reynolds 2004, Burgess 2006) identifies four main critical values to assess when analysing plant response analysis to rainfall pulses: the effective rainfall amount needed for actually modifying plant water status, the response size describing the change in plant water status, the response delay for the time needed for the plant respond to this effective rainfall, and the decay rate for the post-rainfall plant water status decay after the plant responded. We identified here a critical rainfall of about 6-8 $\mathrm{mm}$ for the plants to respond, with no response delay, a response size of about $3 \mathrm{MPa}$ depending on the rainfall intensity and a decay rate of $0.3 \mathrm{MPa}$.day- 1 corresponding to the actual evapotranspiration rate in summer. Irrigation experiments with different rain intensities would allow for a better understanding of specific responses for climate change impact assessment. 
3.3 Ecohydrologically-sound drought quantification

Quantifying drought for climate change studies remain a key challenge to provide valuable information for agriculture and ecosystems (Dai et al. 2001). From global scale studies using generic indices as SPI and SPEI as indicator of major ecosystem functioning (Vicente-Serrano et al 2012), local scale studies point out the weaknesses of these indices for an accurate quantification of drought due to soil and ecophysiological processes (Keyantah and Dracup 2002). Plant-soil water budget models remain the best tools to provide information when climate, soil and plant information are available, and provide continuous information on plant predawn water potential when discrete measurments are time consuming (Zweifel et al. 2005). Water stress integral (WSI) (Myers et al. 1988) is now increasingly used for quantifiying drought features in rainfall interception experiments (Wullschleger et al. 2006, Nepstad et al. 2007) or regional assessments (Ruffault et al. 2013, 214). We recommend here this index as a tool for effective comparison between treatments in rainfall interception experiment as an integrated index accounting for rain pulses.

\subsection{Rainfall interception issues and recommendations}

From our analysis we could quantify the actual impact of the rainfall manipulation based on an ecohydrologically-sound index, the Water Stress Integral. This index allowed us to assess the seasonal impact of the experiment and its overall efficiency. This index was also used as an indicator of potentials biases of the experiment. We identified:

- i) some difficulties to create spring drought right after the starting of the experiment. In march, ETO is still low while soil water content is at field capacity. We managed to desiccate the upper soil layers, but it was difficult to dry out the 
deeper soil layers. We suspect some capillarity effect in this deeper layer with lateral water flows, particularly at the boundary with the non fragmented rock layer where drained water from the upslope might follow this surface and keep wet until soils from the whole watershed is fully drained with a significant time lag after the last rainfall event. Upward capillarity from this boundary to the deeper layers might occur as observed in sites where a water table is observed (Nepstad). In turn, winter water deficit limiting this drainage might actually be more significant on this period than the spring water deficit itself (Yaseef et al. 2009). Fewer fine roots in this deeper layer, combined with reduced evaporation might also limit water uptake and keep this layer humid longer than the upper ones. Low differences in plant water status was also observed in spring for a similar rainfall interception under Mediterranean climate (Ramirez et al. 2012) but hardly assessed or quantified.

- $\quad$ ii) side effects might occur so that individual plants in the center of the plot experience a more intense drought that the external ones. Despite keeping a safety band of $1 \mathrm{~m}$ inside the plot, we hypothesised both some raindrops insertions during windy conditions are able to rehydrate the upper soil layers, and that the lateral spread of the rooting system could reach soil water outside the experiment. This processes has been suggested by Throop et al. (2012) and lateral root profile analysis in mediterranean ecosystems could support this hypothesis (Canadell and Zedler 1995). The experimental protocol was designed to keep a safety band of $1 \mathrm{~m}$ inside the plot, and to dig trench around the plots, but these might not be sufficient for a total interception. This was evidenced by the high standard deviation of plant water potentials after rainfall events inside the plots. Our simulations evidenced that only a $20 \%$ entrance of external rainfall under the roof would significantly modify the water potential of plants located close to the side of the plot.

We'll conclude this analysis that rainfall interception in shrublands are efficient tools to assess the effects of increasing drought on ecosystem functioning. However, we warn here that a full understanding of the deep soil layer water 
budget might mitigate the expected impact due to lateral water movement when soils a fully humid after the winter season. In turn the rainfall interception is more efficient in the rewetting season in fall. Also, fine temporal scale measurements of plant water status in the dry plots after rainfall events would be a valuable information to quantify any side effect, and anisohydric species could be target individual to quantify these effects.

\section{Conclusion}

We performed here a total rainfall interception experiment on a maquis shrubland under Mediterranean climate, with a thorough understanding of the soil and plant water budget. We could propose an accurate water budget model able to simulate both the soil water content, and plant responses in term of predawn leaf water potential (LWP), a key variable for leaf gaz exchange and the subsequent plant carbon budget, growth or cavitation and branch die back. Our results could identify the more significant role of small rainfall events during the dry period when compared to the low impact of rainfall interception on the spring soil desiccation rate. Also the minimum threshold of LWP reached and kept constant all along the season whatever the treatment was not a key indicator in our shallow soil. We identified also limitations in experimental design with scheduled and regular field measurement and rainfall interception systems efficiency. Sparse measurements of LWP can be misleading and more emphasis should be devoted to pre/post rainfall events. Deep soil water movements and side effects on intrusive rain drops should be addressed in details for a more precise quantification of the actual experiment efficiency. The importance of these effects might be heterogeneous according to soil depth, slope or wind and water budget models could be valuable tools to investigate these effects. Watering experiments might in turn be more effective and more easy to control (Wu et al. 2011) 


\section{$1 \quad$ Acknowledgements}

2 This research was funded by EU FP7 program FUME "Forest Fires under Climate, 3 Social and Economic changes in Europe, the Mediterranean and other fire-affected

4 areas of the world" contract grant $\mathrm{N}^{\circ}$ 243888. We thank J.M Moreno for constructive 5 discussions about the experimental design, and the Tunisian forest services ( $\mathrm{Mr} \mathrm{S}$.

6 Belhadj Salah, Direction Générale des Forêts, Tunis, Tunisia) for authorizations to 7 install the experiment. 
Ackerly D. 2004. Functional strategies of chaparral shrubs in relation to seasonal water deficit and disturbance. Ecological Monographs 74(1): 25-44.

Allen R.G., Pereira L.S., Raes D., Smith M. 1998. Crop evapotranspiration - guidelines for computing crop water requirements. Food and Agriculture Organization of the United Nations. Rome.

Ameglio T., Archer P., Cohen M., Valancogne C., Daudet F.A., Dayau S., Cruiziat P. 1999. Significance and limits in the use of predawn leaf water potential for tree irrigation. Plant and soil 207:155-167.

Belk E.L., Markewitz D., Rasmussen T.C., Maklouf Carvalho E.J., Nepstad D.C., Davidson E.A. 2007. Modelling the effetcs of throughfall reduction on soil water content in a brazilian Oxisol under a moist tropical forest. Water Resour. Res. 43, W08432, doi:10.1029/2006WR005493

Beier C., Beierkuhnlein C., Wohlgemuth T., Penuelas J., Emmett B., Kömer C., deBoeck H., Hesselbjerg Christensen J., Leuzinger S., Janssens I.A., Hansen K. 2012. Precipitation manipulation experiments - challenges and recommendations for the future. Ecology Letters 15: 899-911.

Burgess S.S.O. 2006. Measuring transpiration responses to summer precipitation in a Mediterranean climate: a simple screening tool for indentifying plant water use strategies. Physiologia Plantarum 127: 404-412.

Canadell J., Zedler P.H. 1995. underground structures of woody plants in Mediterranean ecosystems of Australia, California, and Chile. In "Ecology and Biogeography of Mediterranean Ecosystems in Chile, California and Australia", Eds Arroyo M.T.K., Zdler P.H., Fox M.D. Springer Verlad, New York, USA. Pp 177-210.

Chakroun H., Mouillot F., Nasr Z., Nouri M., Ennajah A., Ourcival J.M. 2014. Perfomance of LAI MODIS and the influence on drought simulation in a Mediterranean forest. Ecohydrology. DOI 10.1002/eco.1426 in press.

Dai A. 2010. Drought under global warming: a review. Wiley interdisciplinary reviews: climate change.

Donovan LA, Richards J.H., Linton M.J. 2003. Magnitude and mechanisms of disequilibrium between predawn plant and soil water potentials. Ecology 84(2): 463470.

Fernandez J.E., Palomo M.J., Diaz Espejo A., Giron I.F. 2003. Influence of partial soil wetting on water relation parameters of the olive tree. Agronomie 23(7): 545-552.

Galmes J., Flexas J., Savé R., Medrano H. 2007. Water relations and stomatal characteristics of mediterranean plants with different growth forms and leaf habits: responses to water stress and recovery. Plant Soil 290:139-155. 
Ghrab M., Gargouri K., Bentaher H., Chartzoulakis K., Ayadi M., Ben Mimoun M., Masmoudi M.M., Ben Mechlia N., Psarras G. 2013. Water relations and yield of olive tree in reponse to partial root zone drying (PRD) irrigation technique and salinity under arid climate. Agricultural water management 123:1-11.

Giorgi F, Lionello P 2008. Climate change projections for the Mediterranean region. Glob Planet Change 63(2-3):90-104

Golluscio RA, Sala OE, Lauenroth WK (1998) Differential use of large summer rainfall events by shrubs and grasses: a manipulative experiment in the Patagonian steppe. Oecologia 115:17-25

Huxman TE, Snyder KA, Tissue D, Leffler AJ, Ogle K, Pockman WT, Sandquist DR, Potts DL, Schwinning S (2004) Precipitation pulses and carbon fluxes in semiarid and arid ecosystems. Oecologia 141:254-268

Jentz A., Kreyling J., Beierkuhnlein C. 2007. A new generation of climate change experiments: events, not trends. Frontiers in Ecology and the evnrionment 5(7):365374

Joffre R, Rambal S, Damesin C (1999) Functional attributes in Mediterranean-type ecosystems. In: Pugnaire FI, Valladares F (eds) Handbook of functional plant ecology. Marcel Dekker Inc., New York, pp 347-380

Keyantash J., Dracup J.A. 2002. The quantification of Drought: an evaluation of drought indices. Bulletin of the American Meterological Society 83: 1167-1180

Lhomme J.P., Rocheteau A., Ourcival J.M., Rambal S. 2001. Non-steady- state modelling of water transfer in a Mediterranean. Agricultural and Forest Meterology 108: 67-83.

Limousin JM, Rambal S., Ourcival JM, Rocheteau A., Joffre R., Cortina R.R 2009. Long term transpiration change change with rainfall decline in a Mediterranean Quercus ilex forest. Global change biology 15(9):2163-2175.

Loik M.E. 2007. Sensitivity of water relations and photosynthesis to summer precipitation pulses for Artemisia tridentate and Purshia tridentata. Plant Ecology 181: 95-108

Misson L, Degueldre D, Collin C, Rodriguez R, Rocheteau A, Ourcival JM, Rambal S (2011) Phenological responses to extreme droughts in a Mediterranean forest. Glob Change Biol 17(2):1036-1048.

Monteith JL. 1965. Evaporation and environment. Symposia of the Society for Experimental Biology 19: 205-224.

Mouillot F., Rambal S., Lavorel S. 2001. A generic process based simulator for Mediterranean landscapes (SIERRA): design and validation exercice. Forest Ecology and Management 147(1): 75-97.

Muller C. 1999. Modelling Soil-Biosphere Interactions, 354 pp., CABI, Cambridge, U.K. 
Myers B.J. 1988. Water stress integral - link between short term stress and long term growth. Tree Physiology. 4: 315-323

Nepstad D.C. Tohver I.M., Ray D., Moutinho P., Cardinot G. 2007. Mortality of large trees and lianas following experimental drought in an amazon forest. Ecology 88(9): $2259-2269$

Ogle K., Reynolds J.F. 2004. Plant responses to precipitation in desert ecosystems: integrating functionnal types, pulses, thresholds, and delays. Oecologia 141: 282-294.

Parra A., Ramirez D.A., Resco V., Velasco A., Moreno J.M. 2012. Modifying rainfall patterns in a Mediterranean shrubland: system design, plant responses, and experimental burning. Int. J. Biometeorol. 56(6):1033-1043.

Penman HL. 1948. Natural evaporation from open water, bare soil and grass.

Proceedings of Royal Society of London A193: 120-145.

Quero J.L., Sterck F.J., Martinez-Vilalta J. 2011. Water use strategies of six co existing Mediterranean Woody species during summer drought. Oecologia 166(1): 45-57.

Ramirez D.A., Parra A., Resco de Dios V., Moreno J.M. 2012. Differences in morphophysiological leaf traits reflect the response of growth to drought in a seeder but not in a resprouter Mediterranean species. Fuctionnal Plant Biology. 39(4): 332-341.

Ruffault J., Martin St Paul N.K, Rambal S., Mouillot F. 2013. Differential regional responses in drought length, intyensity and timing to recent climate changes in a Mediterranean forest ecosystem. Climatic change: 117:103-117.

Sala OE, Lauenroth WK (1982) Small rainfall events-an ecological role in semi-arid regions. Oecologia 53:301-304

Schwinning S, Ehleringer JR 2001. Water use trade-offs and optimal adaptations to pulse-driven arid ecosystems. J Ecol 89:464-480

Schwinning S., Sala O.E. 2004. Hierarchy of responses to resource pulses in semi arid ecosystems. Oecologia 141(2): 211-220.

Shuttleworth WJ. 2007. Putting the 'vap' into evaporation. Hydrology and Earth System Sciences 11(1): 210-244.

Tardieu F, Simmonneau T (1998) Variability among species of stomatal control under fluctuating soil water status and evaporative demand: modelling isohydric and anisohydric behaviours. J. Exp Bot 49:419-432

Throop H.I., Reichmann L.G., Sala O.E., Archer S.R. 2012. Response of dominant grass and shrub species to water manipulation: an ecophysiological basis for shrub invasion in a Chihuahuan Desert Grassland. Oecologia 169:373-383.

Van Genuchten M.T. 1980. A closed form equation for predicting the hydraulic conductivity of unsaturated soils. Soil Science Society of America Journal. 44:892-898.

Vicca S., Gilgen A.K., Camino Serrano M., Dreesen F.E., Dukes J.S., Estiarte M., Gray S.B., Guidolotti G., Hoeppner S.S., Leakey A.D.B., Ogaya R., Ort D.R., Ostrogovic 
M.Z., Rambal S., Sardans J., Schmitt M., Siebers M., Van der Linden L., van Straaten O., Granier A. 2012. Urgent need for a common metric to make precipitation manipulation experiments comparable. New Phytologist 195:518-522.

West A.G., Dawson T.E., February E.C., Midgley G.F., Bond W.J., Aston T.L., 2012. Diverse functionnal responses to drought in a Mediterranean-type shrubland in south Africa. New Phytologist 195:396-407.

Wu Z., Dijkstra P., Koch G.W., Penuelas J., Hungate B.A. 2011. Responses of terrestrial ecosystems to temperature and precipitation change: a meta-analysis of experimental manipulation. Global Change Biology 17:927-942.

Wullschleger S.D., Hanson P.J. 2006. Sensitivity of canopy transpiration to altered precipitation in an upland oak forest: evidence from a long term manipulation study. Global Change Biology 12(1): 97-109

Yaseef N.R., Yakir D., Rotenberg E., Chiller G., Cohen S. 2009. Ecohydrology of a semi arid forest: partitioning among water balance components and its implications for predicted precitpitation changes. Ecohydrology DOI: 10.1002/eco.65

Zweifel R., Zimmermann L., Newbery D.M. 2005. Modeling tree water deficit from microclimate: an approach to quantifying drought stress. Tree physiology 25: 147-156. 
Figure legend:

Figure1: Location of the Souk el Jema study site in Northern Tunisia.

Figure 2: daily time course of minimum, maximum and mean temperature $\left({ }^{\circ} \mathrm{C}\right)$ (black line with grey shade), global solar radiation (KJ.m-2.day-1)(dotted line) and precipitation $(\mathrm{mm})$ (histogram) registered at meteorological station in the Souk el Jema study site for years 2011 and 2012.

Figure 3: Daily soil water storage $(\mathrm{mm})$ for layer $1(0-5 \mathrm{~cm})$, layer $2(5-15 \mathrm{~cm})$ and layer $3(15-45 \mathrm{~cm})$ registered from automated probes for EC (black line) and SD (dotted line) treatments for the rainfall exclusion period in 2011 and 2012. Daily precipitations are also shown.

Figure 4: A) Daily total soil water content $(\mathrm{mm})(0-45 \mathrm{~cm})$ registered (black line) and simulated (dotted line) for the EC (a,b) and SD (e,f) for years 2011 and 2012, and leaf predawn water potentials (LWP +/- Standard Deviation) (MPa) measured for Arbutus unedo (black dots) and Erica arborea (empty dots) in the EC (c,d) and SD (g,h) and simulated (black line) with LAl values varying between 1.8 and 2.2 (grey shade). B) relationship between observed and measured predawn Leaf Water Potentials (Arbutus unedo black dots, Erica arborea empty dots) for EC and SD treatments for years 2011 and 2012. R-square values, 1:1 line and regression line (dotted) are also shown.

Figure 5: Measured and simulated predawn leaf water potential (LWP) (MPa) for Arbutus unedo (black dots) and Erica arborea (empty dots) before and after the $30 \mathrm{~mm}$ irrigation event on day of the year (DOY) 194 and the $3.8 \mathrm{~mm}$ rainfall event on DOY 205 in 2012.

Figure 6: Measured predawn leaf water potentials (LWP) (MPa) for Arbutus unedo (black dots) and Erica arborea (empty dots) and simulated LWP for total rainfall interception (SD H1) and experimental bias SD H2 (hypothesis that 20\% rainfall reach the plot with shelters) and SD H3 (hypothesis SD H2 + lateral water movement in the deeper layer) 
Figure 1

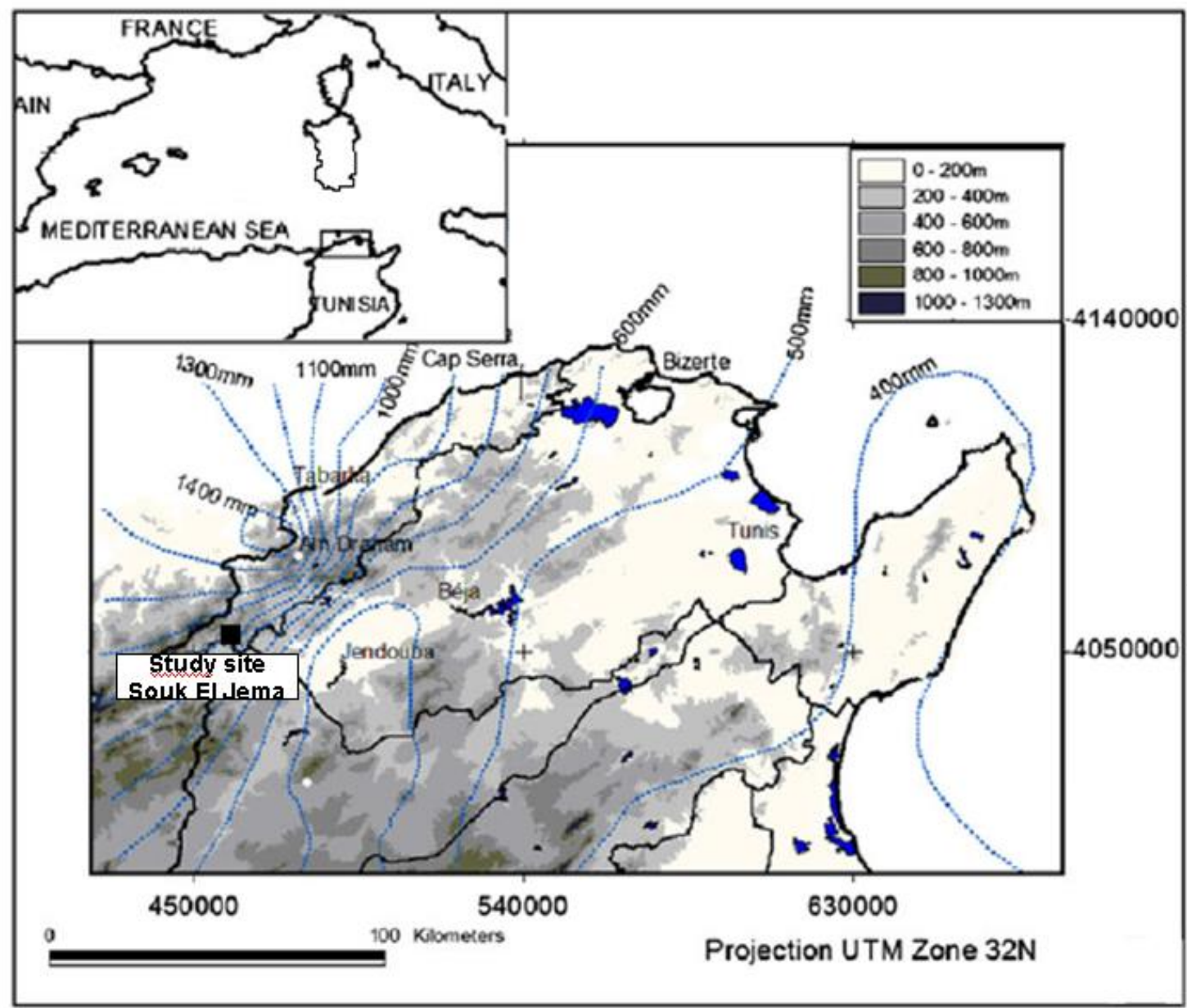


$1 \quad$ Figure 2

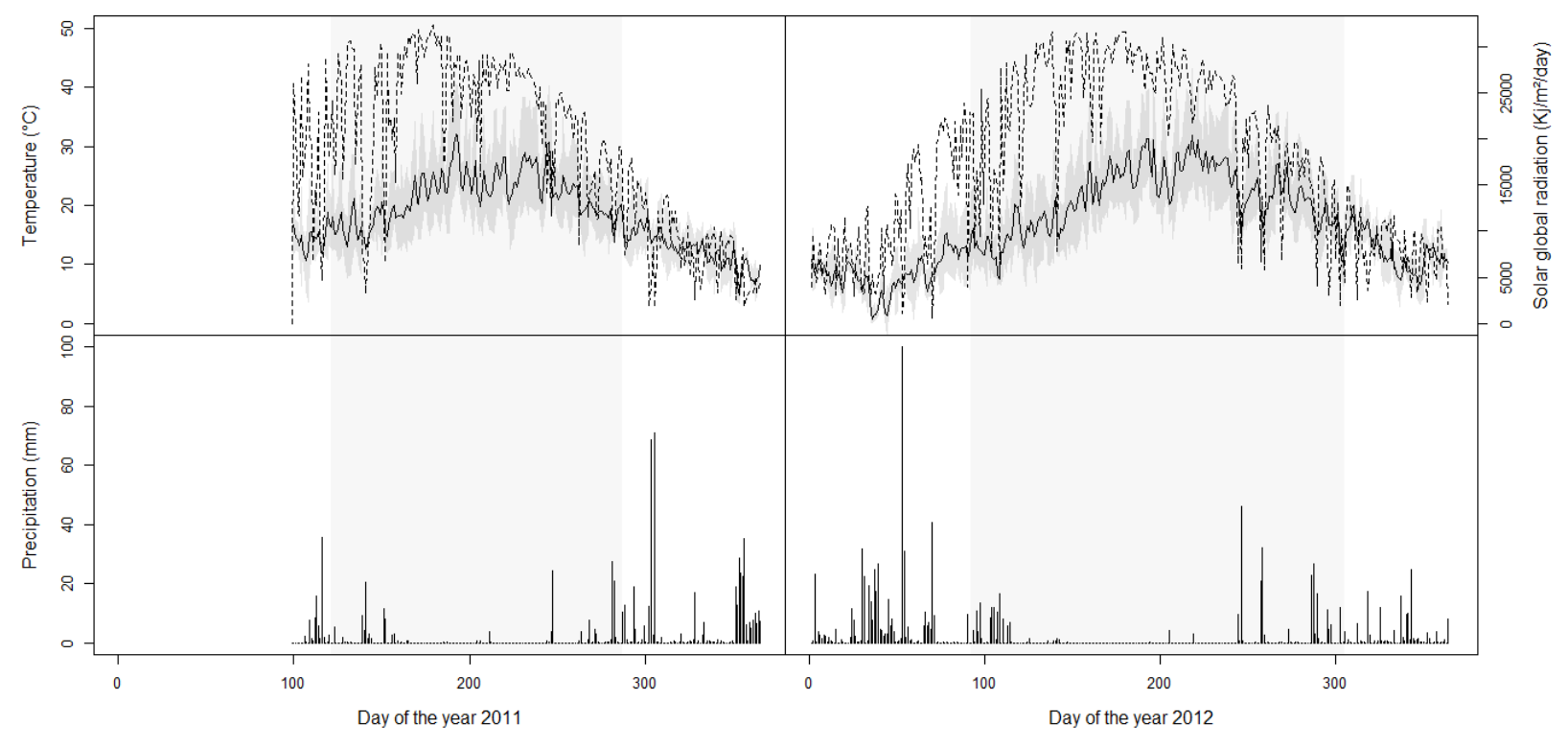




\section{Figure 3}

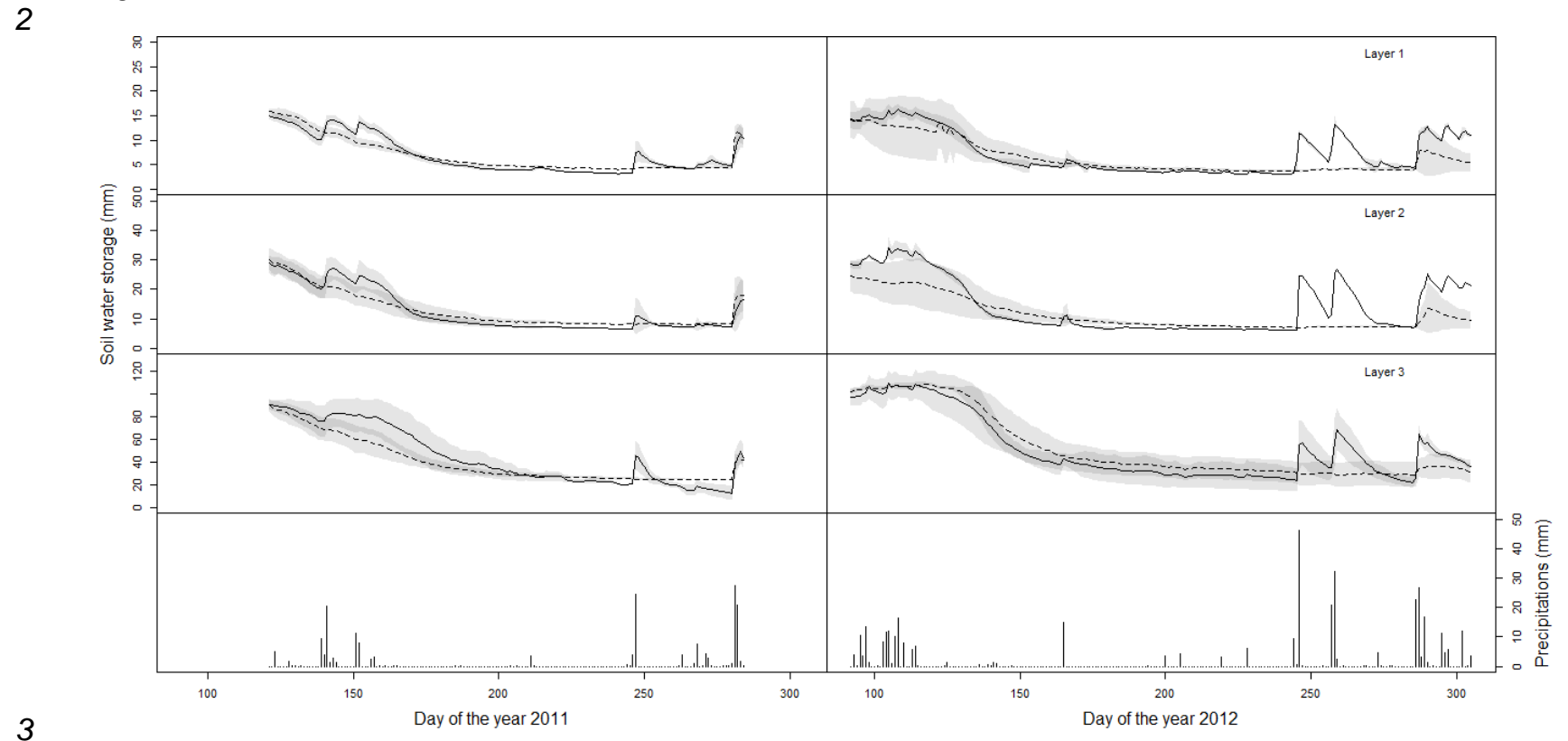


1 Figure4

$2 A$

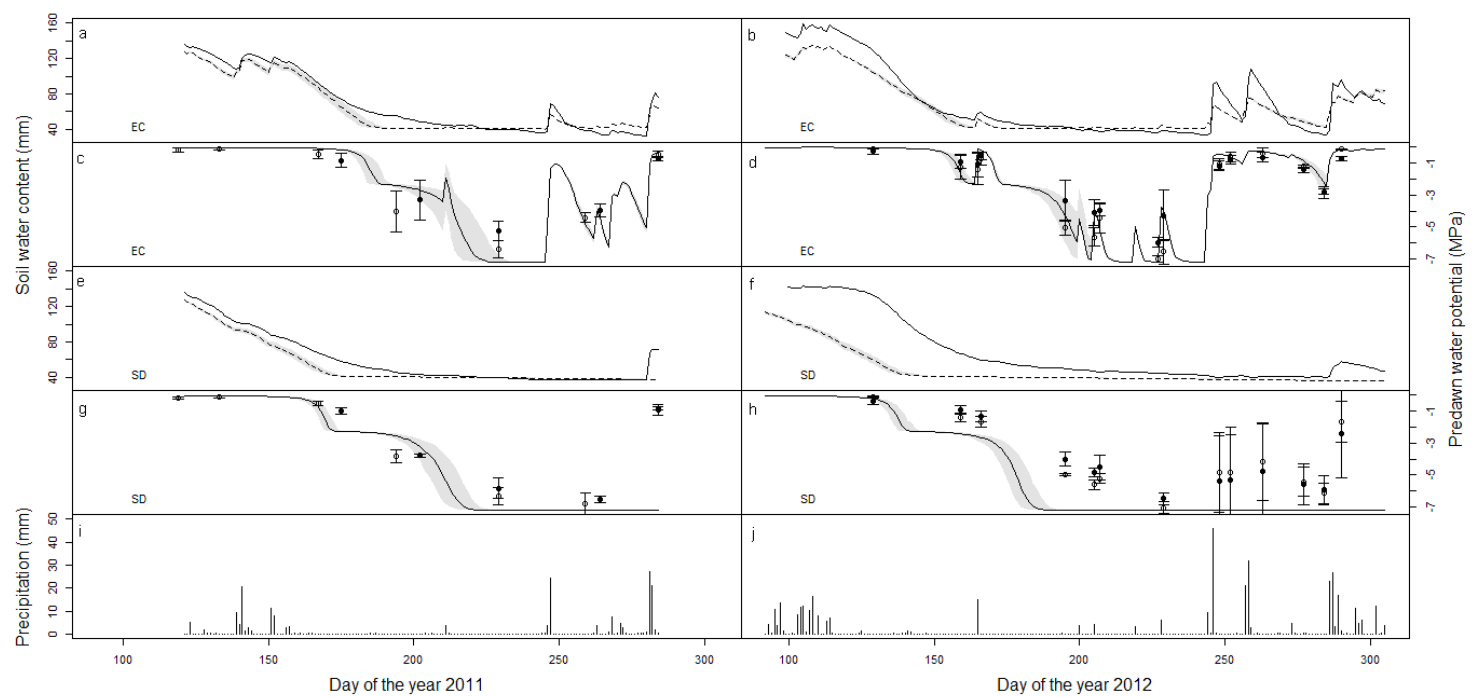

$\begin{array}{ll}3 & \\ 4\end{array}$

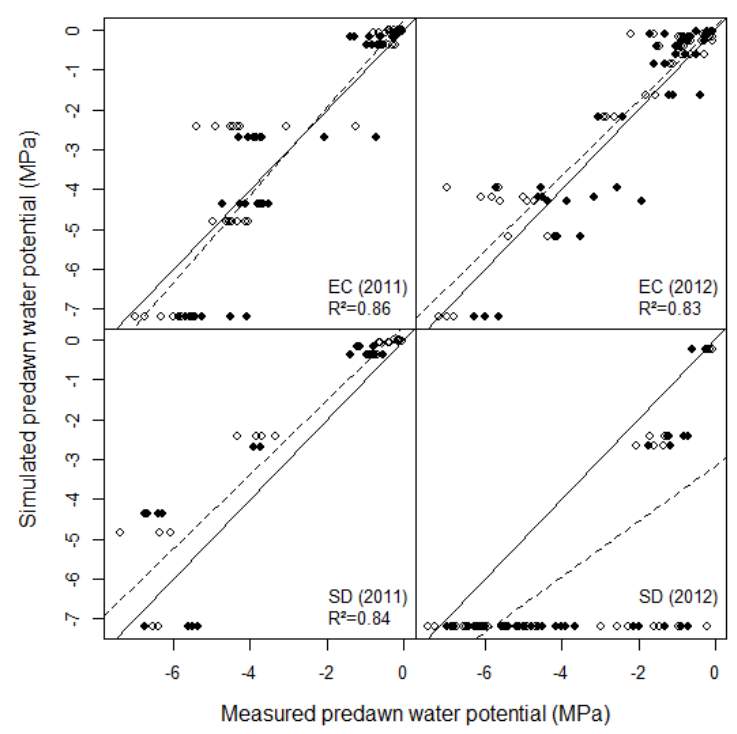

5 
figure 5

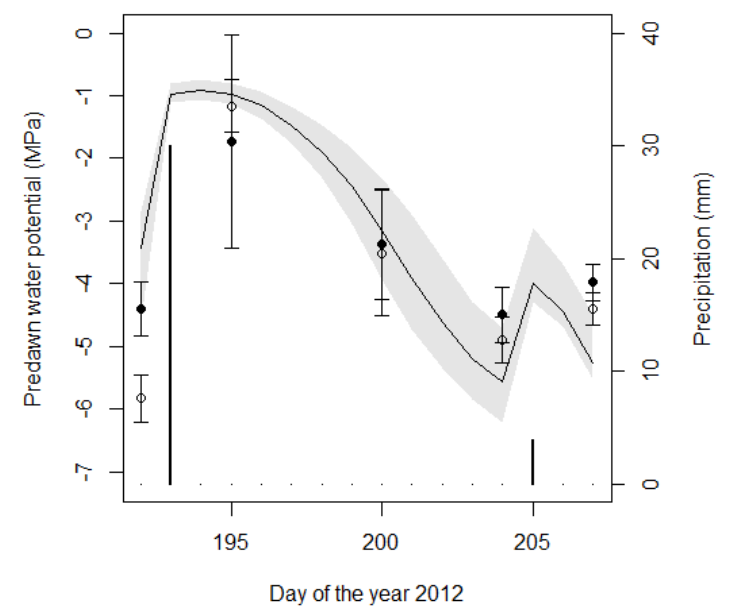

2 
1 Figure 6

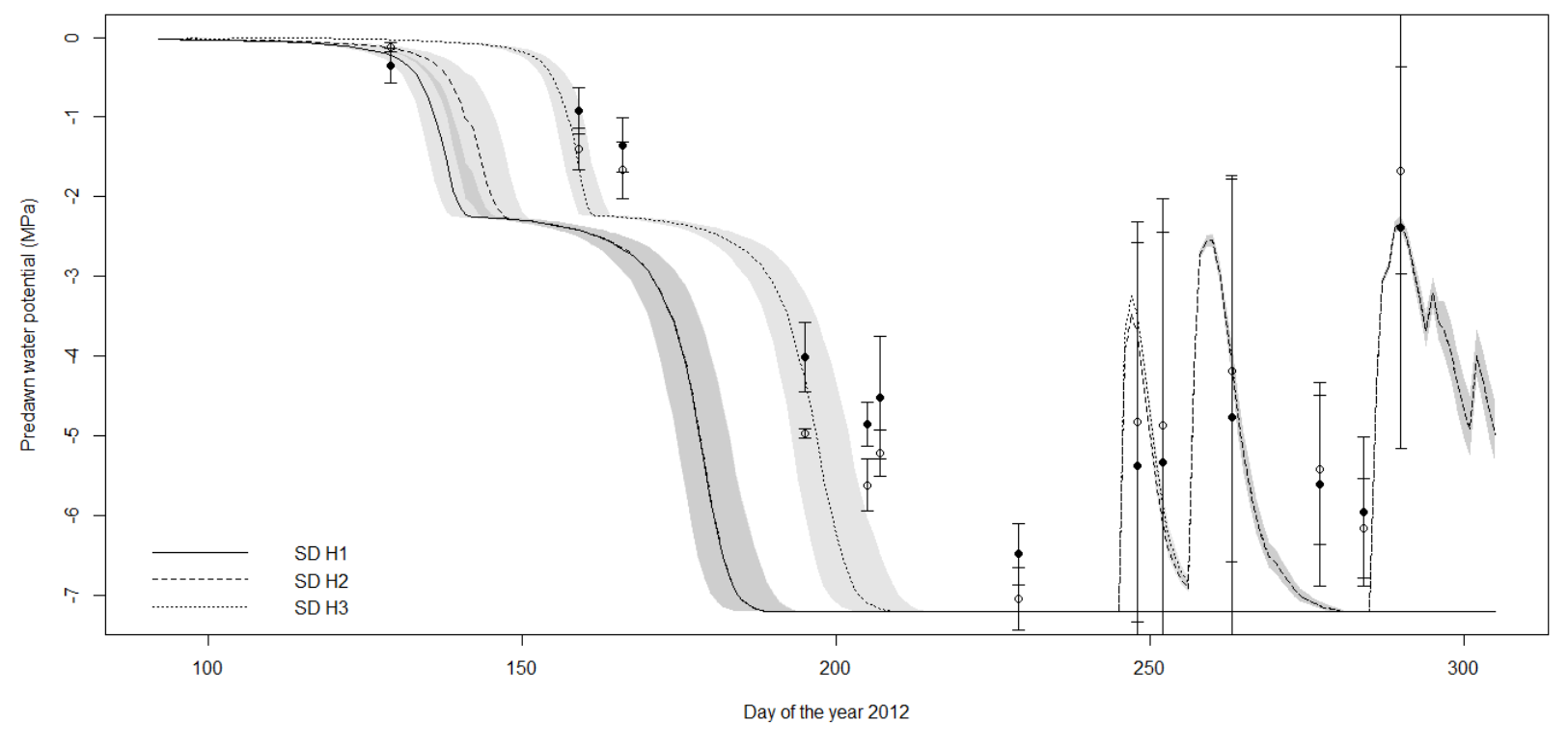

2 
$1 \quad$ Figure 7

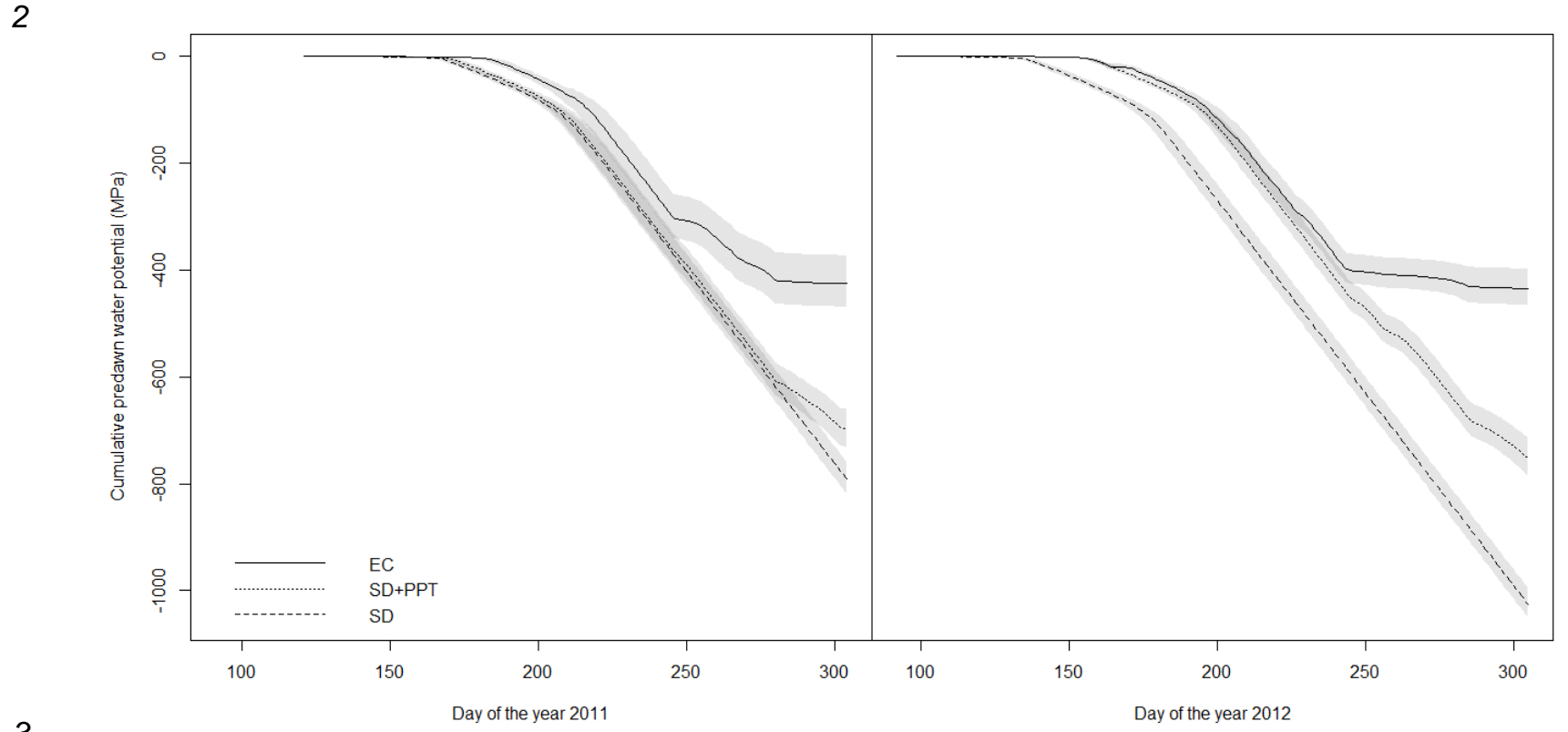

3
4 